\title{
Seleção e caracterização de estirpes de Bacillus thuringiensis tóxicas a Agrotis ipsilon
}

\author{
Rafael Silva Menezes ${ }^{1}$ \\ Vinícius Fiúza Dumas ${ }^{2}$ \\ Érica Soares Martins ${ }^{3}$ \\ Lílian Botelho Praça ${ }^{4}$ \\ Rose Gomes Monnerat ${ }^{5}$
}

\section{Resumo}

Agrotis ipsilon (Lepidoptera: Noctuidae), conhecida como lagarta rosca, é uma praga polífaga e cosmopolita, causadora de sérios danos em cultivos hortícolas e em sistemas de produção de grãos. Uma das alternativas para o combate a essa praga pode ser a utilização de produtos a base de Bacillus thuringiensis (Bt), bactéria aeróbica, Gram positiva, caracterizada pela produção de proteínas tóxicas a insetos. A Embrapa Recursos Genéticos e Biotecnologia possui uma coleção de cerca de 2.300 estirpes de Bt. Neste trabalho, cem estirpes dessa coleção foram testadas para controle de A. ipsilon e, destas, nove foram bastante tóxicas. Essas estirpes pertencem aos sorotipos kurstaki, aizawai, sotto e galleriae. A análise molecular e proteica mostrou a presença dos genes cry1Aa, cry1Ab, cry1Ac, cry1B, cry $1 C$, cry $1 F$, cry 2 e cry 11 e suas respectivas proteínas, indicando serem essas as proteínas envolvidas na atividade tóxica das estirpes selecionadas.

Palavras-chave: Hortaliças. Proteínas Cry. Controle biológico.

1 MSc. Ciências Agrárias. Universidade de Brasília - UnB; e-mail:.

2 MSc. Biologia Molecular - UnB; e-mail: vfdumas@yahoo.com.br.

3 PhD Biologia Molecular - UnB; e-mail: erica_martins@pop.com.br

4 MSc. Agronomia - UnB. Assistente do Centro Nacional de Recursos Genéticos, EMBRAPA; e-mail: lilian@cenargen.embrapa.br

${ }^{5} \mathrm{PhD}$ Agronomia. Ecole Nacionale Agronomique de Montpellier. Pesquisadora da Embrapa Recursos Genéticos e Biotecnologia; e-mail: rose@cenargen.embrapa.br 


\section{Introdução}

Agrotis ipsilon (Lepidoptera: Noctuidae), conhecida como lagarta rosca, é uma praga polífaga e cosmopolita causadora de sérios danos em cultivos hortícolas e em sistemas de produção de grãos. Segundo Souza (2005), o dano causado pelo inseto é maior se a população de lagartas, em estágio de desenvolvimento avançado, for alta. O que é comum de acontecer em Sistemas de Plantio Direto (SPD), no qual o solo é mantido sob cobertura permanente com diversas culturas em sucessão e sem revolvimento, protegendo pupas e adultos desse inseto.

O controle da lagarta rosca, normalmente, é realizado com aplicação de inseticidas químicos logo no início da infestação; contudo, sabe-se que o uso constante e indiscriminado de inseticidas pode causar desequilíbrios ecológicos, seleção de populações de insetos resistentes e perdas econômicas (ALVES; SERIKAWA, 2006). Uma das alternativas para o combate a essa praga pode ser a utilização de produtos a base de Bacillus thuringiensis $(\mathrm{Bt})$. Essa bactéria pertence à família Bacillaceae, é aeróbica, Gram positiva e caracterizada pela produção de inclusões proteicas cristalinas (proteínas Cry), durante seu ciclo de crescimento, no momento de sua esporulação (SCNEPF et al., 1998). As inclusões cristalinas de Bt contêm proteínas denominadas delta-endotoxinas ou proteínas Cry, que, atualmente, formam uma família com mais de 400 membros, classificados em 60 grupos. A atividade tóxica dessas proteínas contra insetos-praga possibilitou o desenvolvimento de bioinseticidas e a seleção de genes codificadores de proteínas inseticidas, utilizados na produção de plantas transgênicas resistentes a insetos. O modo de ação das proteínas Cry tem sido extensivamente estudado e sabe-se que, após a ingestão, essas proteínas (protoxina), são solubilizadas, devido ao $\mathrm{pH}$ alcalino intestinal (CHARLES et al., 2000) e ativadas por proteinases intestinais. Após ser ativada, a proteína reconhece e se liga aos receptores de membrana específicos, causando alterações na permeabilidade, levando a um choque osmótico e, consequentemente, à paralisia e morte do inseto por inanição e septicemia (MONNERAT; BRAVO, 2000; SILVA-WERNECK; MONNERAT, 2001).

Em todo o mundo, são pesquisadas novas estirpes de B. thuringiensis, visando o aumento do número de toxinas disponíveis para o controle de insetos. A Embrapa Recursos Genéticos e Biotecnologia possui em torno de 2.300 
estirpes em sua Coleção de Bactérias Tóxicas a Invertebrados (MONNERAT et al., 2001).

Este trabalho teve como objetivo selecionar estirpes de B. thuringiensis tóxicas da lagarta rosca. As estirpes tóxicas foram caracterizadas por meio de métodos sorológicos, bioquímicos e moleculares para identificação das proteínas Cry responsáveis pela atividade tóxica.

\section{Material e métodos}

Insetos: A colônia de A. ipsilon foi iniciada a partir da aquisição de lagartas da empresa BUG Agentes Biológicos, localizada em Piracicaba - São Paulo. A criação foi realizada no Laboratório de Criação Massal de Insetos, do Núcleo de Controle Biológico da Embrapa Recursos Genéticos e Biotecnologia, numa sala que foi mantida à temperatura de $27 \pm 2^{\circ} \mathrm{C}$, umidade relativa (UR) de $60 \pm 10 \% \mathrm{e}$ fotofase de 14h. Para a obtenção de ovos, adultos foram colocados em gaiolas de PVC (10 cm de diâmetro por $20 \mathrm{~cm}$ de altura), fechadas na extremidade superior com filó e, na inferior, com placa de Petri. Os ovos foram coletados diariamente e colocados em recipiente plástico adequado, com furo nas tampas, que permitia a passagem do ar, e com dieta artificial, que serviu para alimentar as larvas recém eclodidas, onde foram mantidas até atingirem o terceiro estágio de desenvolvimento. As larvas de terceiro estágio foram trocadas de recipientes plásticos, contendo dieta artificial, onde foram mantidas até empuparem. A dieta foi preparada de acordo com a composição estabelecida pela empresa BUG Agentes Biológicos (feijão $75 \mathrm{~g}$, gérmen de trigo $60 \mathrm{~g}$, proteína de soja $30 \mathrm{~g}$, caseína $30 \mathrm{~g}$, levedo de cerveja 37,5g, solução vitamínica 9mL, ácido ascórbico 3,6g, ácido sórbico 1,8g, nipagin $3 \mathrm{~g}$, tetraciclina $0,11 \mathrm{~g}$, formol $3,6 \mathrm{~mL}$, ágar $27 \mathrm{~g}$ e $1,2 \mathrm{~L}$ de água destilada). As pupas eram então coletadas e colocadas nas gaiolas de PVC. Os adultos foram alimentados diariamente com solução aquosa de mel a $10 \%$.

Estirpes de Bacillus thuringiensis: Cem estirpes de B. thuringiensis, pertencentes à Coleção de Bactérias Tóxicas a Invertebrados da EMBRAPA Recursos Genéticos e Biotecnologia (MONNERAT et al., 2007), originárias de amostras de 
solo e água de diferentes regiões do país, e previamente identificadas como patogênicas, as espécies da ordem Lepidoptera foram utilizadas neste trabalho. Essas estirpes haviam sido previamente sorotipadas pelo Instituto Pasteur de Paris.

Bioensaios: As estirpes foram crescidas em meio NYSM (YOUSTEN, 1984) em agitador rotativo a $28^{\circ} \mathrm{C}, 200 \mathrm{rpm}$ em agitador rotativo (New Brunswick Scientific Co.) por $72 \mathrm{~h}$. Os bioensaios foram realizados, espalhando-se $35 \mu \mathrm{L}$ do cultivo de cada estirpe de $B$. thuringiensis, contendo tanto esporos quanto cristais, sobre a superfície da dieta artificial $(2 \mathrm{~mL})$ distribuída previamente em placas de cultivo de células com 24 poços. Após a absorção da mistura de esporos e cristais pela dieta do inseto, lagartas de segundo ínstar foram adicionadas às placas, sendo colocada uma lagarta para cada poço, já que as mesmas podem adotar comportamento canibal. Em seguida, os insetos foram deixados em câmara climatizada à temperatura de $27 \pm 2{ }^{\circ} \mathrm{C}$, UR de $60 \pm 10 \%$ e fotofase de $14 \mathrm{~h}$. Uma placa foi mantida sem a cultura bacteriana, como testemunha. A primeira avaliação (verificação do número de lagartas mortas) foi feita em 48 h após o início do ensaio, ocasião em que as lagartas vivas foram transferidas individualmente para copos de plástico de $50 \mathrm{~mL}$, contendo pedaços de aproximadamente $1 \mathrm{~cm}^{3}$ de dieta sólida, livre do bacilo. No quinto dia do ensaio, foi feita a segunda e última avaliação (Monnerat et al., 2001). As estirpes que causaram no mínimo $70 \%$ de mortalidade foram selecionadas para a continuidade do trabalho.

Caracterização das estirpes de Bacillus thuringiensis tóxicas: As estirpes que causaram no mínimo 70\% de mortalidade foram caracterizadas quanto ao sorotipo, perfil de proteínas e presença de genes cry.

Caracterização sorológica: As estirpes foram caracterizadas de acordo com o protocolo descrito por de Barjact e Frachon (1991). Os soros utilizados foram gentilmente cedidos pelo Instituto Pasteur, Paris. Quatro das estirpes tóxicas haviam sido previamente sorotipadas pelo Instituto Pasteur de Paris e foram utilizadas como controle positivo.

Caracterização de proteínas através de SDS-PAGE: A caracterização bioquímica das estirpes foi realizada por meio de eletroforese de proteínas em gel de 
poliacrilamida (SDS-PAGE 10\%). As proteínas foram obtidas segundo protocolo descrito por Lecadet et al. (1991), a partir de material crescido em meio NYSM por $72 \mathrm{~h}$ a $200 \mathrm{rpm}$ em agitador rotativo (New Brunswick Scientific Co.) a $28{ }^{\circ} \mathrm{C}$. A estirpe HD-1 de B. thuringiensis subsp. kurstaki (Btk) foi utilizada como padrão.

Caracterização molecular: As estirpes selecionadas foram caracterizadas quanto à presença de genes codificadores de proteínas Cry. Para isso, foram realizados testes de PCR (reação em cadeia da polimerase), utilizando oligonucleotídeos gerais desenhados para os genes cry1, cry2, cry3, cry4 e cry11 (IBARRA et al., 2003) e específicos para identificação de cry1, cry4 e cry9 (CERON et al., 1994; 1995; BRAVO et al., 1998).

A extração de DNA foi realizada a partir de adaptação do protocolo descrito por Sambrook et al. (1989). As reações de PCR foram realizadas em tubos de polipropileno 0,2 mL, em um termociclador MJ Research, Inc. (PTC-100 ${ }^{\mathrm{TM}}$ ). Foram transferidos $10 \mu \mathrm{L}$ de DNA de cada amostra para um tubo de polipropileno, contendo 8,0 $\mu \mathrm{M}$ de cada oligonucleotídeo específico, $5 \mathrm{mM}$ de dNTP mix, tampão de Taq 10x e 2,5 U de Taq DNA polimerase para uma reação de 50 $\mu \mathrm{L}$. As condições de amplificação foram descritas por Ceron et al. (1994 e 1995), Bravo et al. (1998)

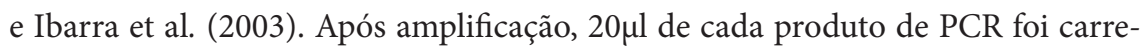
gado em gel de agarose 1,5\%, corado com brometo de etídio e visualizado em luz ultravioleta. As estirpes HD-1 de B. thuringiensis, subespécie kurstaki e IPS-82 de B. thuringiensis subespécie israelensis, foram utilizadas como padrão.

\section{Resultados e discussão}

Das cem estirpes de B. thuringiensis testadas, seis causaram 100\% de mortalidade e três causaram mortalidade de $75 \%$ nos bioensaios seletivos. Dentre as estirpes que causaram mortalidade de $100 \%$, quatro haviam sido previamente sorotipadas e pertenciam aos sorotipos galleriae (S597), sotto (S615), aizawiai (S616), kurstaki (S1450), descritos na literatura como tóxicos a insetos da ordem Lepidoptera (PRAÇA et al., 2006, MONNERAT et al., 2007). As estirpes (S907 e S1168), que também causaram 100\% de mortalidade, foram sorotipadas neste trabalho. A estirpe S 1168 
foi sorotipada como kurstaki e a S907 não reagiu com nenhum dos sorotipos testados, indicando pertencer a uma nova classe. As estirpes S234, S844 e S906 causaram mortalidade de 75\%. A estirpe S234 foi sorotipada como Bt sotto; S844 não reagiu com nenhum dos sorotipos testados e a S906 foi autoaglutinante (Tabela 1).

Tabela 1 - Estirpes, sorotipos, porcentagem de mortalidade e perfil molecular e protéico das estirpes de B. thuringiensis selecionadas.

\begin{tabular}{|c|c|c|c|c|}
\hline Estirpes & Sorotipo & $\begin{array}{l}\% \\
\text { Mortalidade }\end{array}$ & $\begin{array}{l}\text { Perfil protéico } \\
(\mathrm{kDa})\end{array}$ & $\begin{array}{l}\text { Perfil molecular } \\
\text { (genes cry) }\end{array}$ \\
\hline S1450 & kurstaki & 100 & 130 e 65 & $\begin{array}{l}\operatorname{cry} 1 A a, \operatorname{cry} 1 A b, \\
\operatorname{cry} 1 A c, \operatorname{cry} 1 B, \operatorname{cry} 2\end{array}$ \\
\hline S1168 & kurstaki & 100 & 130 & $\operatorname{cry} 1 A a$ \\
\hline S907 & Não reagente & 100 & 140 & $\operatorname{cry} 1 B$ \\
\hline S616 & aizawai & 100 & 130 & $\begin{array}{l}\operatorname{cry} 1 A a, \operatorname{cry} 1 A b, \\
\operatorname{cry} 1 F\end{array}$ \\
\hline S234 & sotto & 75 & 130 e 65 & $\begin{array}{l}\operatorname{cry} 1 A a, \operatorname{cry} 1 A b, \\
\operatorname{cry} 1 A c, \text { cry } 1 B, \text { cry } 2\end{array}$ \\
\hline S906 & $\begin{array}{l}\text { auto- } \\
\text { aglutinante }\end{array}$ & 75 & 140 & $\operatorname{cry} 1 B$ \\
\hline S615 & sotto & 100 & 130 & $\begin{array}{l}\operatorname{cry} 1 A b, \operatorname{cry} 1 A c, \\
\operatorname{cry} 1 B\end{array}$ \\
\hline S597 & galleriae & 100 & 130 & $\operatorname{cry} 1 \mathrm{C}$ \\
\hline S844 & Não reagente & 75 & 72 e 65 & cry2, cry 11 \\
\hline
\end{tabular}

Praça et al. (2003), em seus estudos sobre prospecção de estirpes de Bt efetivas contra insetos da ordem Lepidoptera, Coleoptera e Diptera, identificaram que a estirpe S234 apresentou toxicidade a Spodoptera frugiperda e Anticarsia gemmatalis (Lepidoptera: Noctuidae), Antonomus grandis (Coleoptera: Curculionidae), Culex quinquefasciatus e Aedes aegypti (Díptera: Culicidae). Vale ressaltar que a $\mathrm{CL}_{50}$ dessa estirpe, nos bioensaios de dose realizados contra $S$. frugiperda, foi três vezes menor do que o padrão B. thuringiensis subsp. kurstaki (S1450). A atividade tóxica das estirpes S844, S906 e S907, a lagartas de A. gemmatalis, inseto-praga, que é o principal causador de danos na cultura da soja no Brasil, foi relatada por Batista et al. (2006). Melatti et al. (2005) demonstraram que S. frugiperda é susceptível à estirpe S615, sendo sua $\mathrm{CL}_{50}$ estimada em $1,04 \mathrm{ng} / \mathrm{cm}^{2}$, mais eficiente que o Btk que apresentou, nos bioensaios realizados, $\mathrm{CL}_{50}$ de $1,34 \mathrm{ng} / \mathrm{cm}^{2}$. 
Das nove estirpes selecionadas neste trabalho e que causaram mortalidade igual ou superior a 75\% nos bioensaios seletivos, as estirpes S234, S615, S616, S844, S906 e S907 já haviam sido identificadas como tóxicas a insetos-praga por Praça et al., (2003), Melatti et al., (2005), Batista et al., (2006) e Melatti (2008).

A análise do perfil protéico, por meio de eletroforese em gel de poliacrilamida (SDS-PAGE) das misturas de esporos e cristais das nove estirpes selecionadas nos bioensaios, revelou bandas entre $130 \mathrm{kDa}$ e de $72 \mathrm{kDa}$, que se equivalem ao perfil esperado do padrão $B$. thuringiensis subsp. kurstaki e dos sorotipos $B$. thuringiensis subsp. galleriae, $B$. thuringiensis subsp. sotto e $B$. thuringiensis subsp. aizawai (HOFTE et al., 1988; LERECLUS et al., 1993) (Tabela 1).

Por meio da técnica de PCR, utilizando iniciadores específicos desenhados para detecção dos genes cry1, cry2, cry3, cry4 e cry11 (IBARRA et al., 2003) e específicos para identificação de cry1, cry4 e cry9 (CERON et al., 1994; 1995; BRAVO et al., 1998), foi possível determinar quais os genes cry de B. thuringiensis estavam presentes nas estirpes. Das nove estirpes selecionadas neste trabalho, as estirpes S234, S844, S906 e S907 já haviam sido caracterizadas quanto à presença dos genes cry, em trabalhos anteriores (PRAÇA et al., 2003, MELATTI et al., 2005, BATISTA, et al., 2006). Nessas estirpes, foram encontrados os genes cry1Aa, cry1Ab, cry1Ac, cry1B, cry2 e cry11. Nas estirpes, que não haviam sido caracterizadas (S597, S615, S616, S844 e S1168), foi identificada a presença de bandas correspondentes aos genes cry $1 A a, \operatorname{cr} y 1 A b, \operatorname{cr} y 1 A c, \operatorname{cr} y 1 B, \operatorname{cr} y 1 C, c r y 1 F, c r y 2$ e cry 11 . A tabela 1 compila todos os resultados dos genes cry presentes nas estirpes tóxicas.

Esses resultados demonstram que diferentes proteínas Cry podem estar envolvidas na atividade tóxica a larvas de A. ipsilon. Contudo, o gene cry $1 B$ foi detectado em cinco das nove estirpes selecionadas. Vale ressaltar que as estirpes $\mathrm{S906} \mathrm{e}$ S907 só possuem o gene cry1B e que, em seu perfil proteico, foi detectada a presença de uma banda de $130 \mathrm{KDa}$., correspondente, ao tamanho esperado para a proteína Cry1B, assim sendo, pode-se considerar ser essa a proteína tóxica a A. ipsilon.

Os genes cry $1 A a$ e cry $1 A b$ foram encontrados em 4 das 9 estirpes. Todas essas estirpes apresentaram perfis proteicos compatíveis com a presença das prote- 
ínas Cry1Aa e Cry1Ab, em torno de 130 KDa. A estirpe S1168 apresentou apenas o gene cry $1 A a$, assim, pode-se considerar que CrylAa é tóxica à lagarta rosca. $\mathrm{O}$ gene $c r y 1 A c$ e $c r y 2$ foram detectados em 3 estirpes, cujos perfis indicaram a presença de suas proteínas correspondentes, respectivamente, de 130 e $65 \mathrm{KDa}$. A estirpe S844 possui os genes cry2 e cry11 e, no seu perfil proteico, foi detectada a presença de uma banda de $65 \mathrm{KDa}$, correspondente à proteína Cry2 e outra de $72 \mathrm{KDa}$, correspondente à proteína Cry11. Esta última proteína está descrita como tóxica a Dípteros (LIMA et al., 2008), já a Cry2 está descrita como tóxica a Lepidópteros, assim, é possível que a proteína tóxica a $A$. ipsilon seja a Cry2.

O gene cry1C foi detectado, na estirpe S597, que apresentou uma banda de $130 \mathrm{KDa}$, compatível com a proteína Cry1C. Essa proteína está descrita como tóxica a diversos insetos da ordem Lepidoptera, tais como a Anticarsia gemmatalis e Spodoptera frugiperda (MONNERAT et al., 1996), mas não está descrita como tóxica a $A$. ipsilon. Esse, portanto, é o primeiro relato da susceptibilidade da lagarta rosca a esta toxina. O gene cry $1 F$ foi encontrado na estirpe S616, que também possui outros genes.

A proteína Cry $1 \mathrm{Ab}$ aparece na literatura como tóxica a diferentes insetos da ordem Lepidoptera, tais como, S. exígua, Heliothis virescens, Pieres brassicae, Manduca sexta, S. frugiperda e A. gemmatalis (BRAVO et al., 2002; MARTENS et al., 1995; PRAÇA et al., 2003). Maagd et al. (2003) não identificaram atividade tóxica das proteínas Cry1Ab e Cry1Ac, em bioensaios com A. ipsilon. Porém, nos trabalhos de Gilliand et al. (2002) reportaram significativa atividade da proteína Cry1Ac, na mortalidade de lagartas de A. ipsilon. Gilliand et al. (2002) também demonstraram atividade tóxica da proteína Cry1Ac e também da Cry1J.

Os trabalhos conduzidos por Maagd et al. (2003) testaram a atividade de doze proteínas Cry1 e duas Cry9, contra lagartas de A. ipsilon. Os resultados obtidos indicaram que a lagarta rosca não foi susceptível à maioria das toxinas analisadas. Porém, entre elas, três apresentaram atividade significativa: Cry 9Ca foi a mais tóxica, seguida por Cry1Aa e Cry1Fb. A proteína Cry 1Aa está presente nas estirpes S234 e S1450 selecionadas nesta pesquisa, confirmando sua possível toxicidade a $A$. ipsilon. 
No trabalho de Gilliand et al. (2002), o grupo reportou significativa atividade da proteína Cry1Ac na mortalidade de lagartas de A. ipsilon. Gilliand et al. (2002) testaram quatro diferentes toxinas Cry, e a proteína Cry1J também demonstrou resultados satisfatórios, além da CrylAc.

As proteínas Cr1 Ab e Cry1 Ac estão presentes nas estirpes S234, S1450 (Btk) e S615. As estirpes S1450 e S615 causaram 100\% de mortalidade, enquanto a S234 causou 75\% nos bioensaios realizados, sugerindo a possível atividade tóxica dessas proteínas contra A. ipsilon.

Entretanto, é muito difícil estabelecer a contribuição de cada toxina, pois a toxicidade de algumas estirpes aos insetos-alvo pode ser devido a interações sinergéticas entre as toxinas encontradas, ou mesmo, pela interação destas com os esporos.

Novos testes devem ser conduzidos com proteínas individuais e em conjunto para que a susceptibilidade de A. ipsilon seja determinada e que assim, os danos causados por essa praga possam ser minimizados. Os resultados aqui apresentados podem contribuir para a formulação de bioinseticidas mais específicos para a lagarta rosca, bem como, na identificação de possíveis genes cry aplicáveis na transformação de plantas com objetivo de conferir resistência genética a esta praga.

\section{Selection and characterization of Bacillus thuringiensis strains toxic to Agrotis ipsilon}

\section{Abstract}

Agrotis ipsilon (Lepidoptera: Noctuidae), known as black cutworm is a polyphagous caterpillar that causes serial damage in agriculture and in systems of grain production. One option for controlling this insect is the use of products based on Bacillus thuringiensis (Bt), a Gram positive, aerobic bacterium, characterized by the production of insecticidal toxins. Embrapa Genetic Resources and Biotechnology has a collection of 2,300 Bt strains. In this work a hundred Bt strains 
from this collection were tested against $A$. ipsilon and nine were very toxic. These strains were serotyped as kurstaki, aizawai, sotto and galleriae. The molecular characterization and protein profile showed the presence of cry $1 A a, c r y 1 A b, c r y 1 A c$, $\operatorname{cry} 1 B, \operatorname{cry} 1 C, \operatorname{cry} 1 F, c r y 2$ and $\operatorname{cry} 11$ genes and proteins of the corresponding molecular weights. These proteins are, therefore, probably involved in the toxic activity of the selected strains.

Keywords: Vegetables. Cry proteins. Biological control.

\section{Referências}

ALVES, A. P.; SERIKAWA, R. H. Controle químico de pragas do algodoeiro. Revista Brasileira de Oleaginosas e Fibrosas, Campina Grande, v. 10, n. 3, p. 1197-1209, 2006.

BATISTA, A. C. Seleção de estirpes de Bacillus thuringiensis e estudos de produção para o desenvolvimento de um bioinseticida visando o controle de pragas agrícolas. 2006. 88 f. Dissertação (Mestrado)-Faculdade de Agronomia e Medicina Veterinária, Universidade de Brasília, Brasília, 2006.

BRAVO, A. et al. Pore formation activity of Cry $1 \mathrm{Ab}$ toxin from Bacillus thuringiensis in an improved membrane vesicle preparation from Manduca sexta midgut cell microvilli. Biochemistry et Biophysical Acta, New York, v. 1562, p. 63-69, 2002. doi:10.1016/S0005-2736(02)00360-7.

BRAVO, A. et al. Characterization of cry genes in Mexican Bacillus thuringiensis strain collection. Applied and Environmental Microbiology, Washington, v. 64, p. 4965-4972, 1998.

CERON, J. et al. PCR analysis of the cryI insecticidal crystal family genes from Bacillus thuringiensis. Applied and Environmental Microbiology, Washington, v. 60, p. 353-356, 1994.

CERON, J. et al. Specific PCR primers directed to identify cryI and cryIII genes within a Bacillus thuringiensis strain collection. Applied and Environmental Microbiology, Washington, v. 61, p. 3826-3831, 1995. 
CHARLES, J. F.; DELECLUSE, A.; NIELSEN-LEROUX, C. Entomopathogenic bacteria: from laboratory to field application. New York: Klumer Academic, 2000.

DE BARJAC, H.; FRACHON, E. Classification of Bacillus thuringiensis strains. Entomophaga, Paris, v. 35, n. 2, p. 233-240, 1990. doi:10.1007/BF02374798.

GILLILAND, A. et al. Role of Bacillus thuringiensis Cryl delta endotoxin binding in determining potency during lepidopteran larval development. Applied and Environmental Microbiology, Washington, v. 68 n. 4, p. 1509-15, 2002. doi:10.1128/AEM.68.4.1509-1515.2002.

HÖFTE, H. et al. Monoclonal antibody analysis and insecticidal spectrum of three types of lepidopteran-specific insecticidal crystal proteins of Bacillus thuringiensis. Applied and Environmental Microbiology, Washington, v. 54, p. 2010-2017, 1988.

IBARRA, J. et al. Diversity of Bacillus thuringiensis strains from Latin America with insecticidal activity against different mosquito species. Applied and Environmental Microbiology, Washington, v.69, p.5269-5274, 2003. doi:10.1128/ AEM.69.9.5269-5274.2003.

LECADET, M.M. et al. Construction of novel Bacillus thuringiensis strains with different insecticidal activities by transduction and transformation. Applied and Environmental Microbiology, Washington, v. 58, p. 840-849, 1991.

LERECLUS, D.; DELÉClUSE, A.; LECADET, M.M. Diversity of Bacillus thuringiensis toxins and genes. In: ENWISTLE, P. F. et al. (Ed.). Bacillus thuringiensis: an environmental biopesticide: theory and practice. Londres: Wiley, 1993. p. 37-69.

LIMA, G. M. S. et al. Cry2A toxins from Bacillus thuringiensis expressed in insect cells are toxic to two lepidopteran insects. World Journal of Microbiology and Biotechnology, New York, v. 24, p. 2941-2948, 2008. doi:10.1007/s11274-0089836-x.

MAAGD, R. A. de et al. Activity of eild-type and hybrid Bacillus thuringiensis $\delta$-endotoxins against Agrotis ipsilon. Archives of Microbiology, New York, v. 179, p. 363-367, 2003. doi: 10.1007/s00203-003-0543-6.

MARTENS, J. W. M. et al. Characterization of baculovirus insecticides expressing tailored Bacillus thuringiensis Cru1A(b) crystal proteins. Journal of Invertebrate Pathology, San Francisco, v. 66, p. 249-267, 1995. doi:10.1006/jipa.1995.1097 
MELATTI, V. et al. Determinação da susceptibilidade de Spodoptera frugiperda a diferentes subspécies de Bacillus thuringiensis. Boletim de Pesquisa e Desenvolvimento da Embrapa Recursos Genéticos e Biotecnologia, Brasília, n. $88,2005$.

MONNERAT, R. G. et al. Characterization of brazilian Bacilus thuringiensis strains active against Spodoptera frugiperda, Plutella xylostella and Anticarsia gemmatalis. Biological Control, San Francisco, v. 41, p. 291 - 295, 2007. doi:10.1016/j. biocontrol.2006.11.008.

MONNERAT, R.G. et al. Genetic variability in Spodoptera frugiperda Smith populations in Latin America is associated to variations in susceptibility to Bacillus thuringiensis Cry toxins. Applied and Environmental Microbiology, San Francisco, v. 72, p. 7029-7035, 2006. doi:10.1128/AEM.01454-06.

MONNERAT, R. G.; SILVA, S. F.; SILVA-WERNECK, J. O. Catálogo do banco de germoplasma de bactérias do gênero Bacillus. Brasília: Embrapa, 2001.

MONNERAT, R.G.; BRAVO, A. Proteínas bioinseticidas produzidas pela bactéria Bacillus thuringiensis: modo de ação e resistência. In: MELO, I.S.; AZEVEDO, J.L. (Ed.). Controle biológico. Jaguariúna: Embrapa-CNPMA, 2000. v. 3. p.163-200.

PRAÇA, L. B. et al. Estirpes de Bacillus thuringiensis efetivas contra insetosdas ordens Lepidoptera, Coleoptera e Diptera. Pesquisa Agropecuária Brasileira, Brasília, v. 39, n. 1, p. 11-16, 2004. doi: 10.1590/S0100-204X2004000100002.

PRAÇA, L. B.; SILVA NETO, S. P.; MONNERAT, R. G. Spodoptera frugiperda J. Smith 1797 (Lepidoptera: Noctuidae) Biologia, amostragem e métodos de controle. Brasília: Embrapa, 2006. (Documentos/Embrapa Recursos Genéticos e Biotecnologia, 199).

SAMBROOK, J.; FRITSCH, E. F.; MANIATIS, T. Molecular cloning: a laboratory manual. 3. ed. New York: Cold Spring Harbor Laboratory, Cold Spring Harbor, 2001 .

SCHNEPF, E. et al. Bacillus thuringiensis and pesticidal crystal proteins. Microbiology and Molecular Biology Reviews, Washington, v. 62, n. 3, p. 775806, 1998.

SILVA-WERNECK, J. O.; MONNERAT, R. Metodologias para caracterização de isolados de Bacillus thuringiensis. Brasília: Embrapa-Cenargen, 2001. (Circular Técnica, v. 10). 
SOUZA, J. C. Principais aspectos sobre as pragas do milho em plantios direto e convencional. Circular técnica da Empresa de Pesquisa Agropecuária de Minas Gerais, Belo Horizonte, n. 180, mar. 2005.

YOUSTEN, A.A. Bacillus sphaericus: Microbiological factors related to its potencial as mosquito larvicide. Advances in Biotechnological Processes, New York, v. 3, p. 315-343, 1984. 
Para publicar na revista Universitas: Ciências da Saúde, acesse o endereço eletrônico www.publicacoesacademicas.uniceub.br. Observe as normas de publicação, para facilitar e agilizar o trabalho de edição. 